\title{
Oral Contraceptives and Periodontal Diseases: Rethinking the Association Based Upon Analysis of National Health and Nutrition Examination Survey Data
}

\author{
L. Susan Taichman* ${ }^{\dagger}$ and Stephen A. Eklund ${ }^{\dagger}$
}

Background: Historic evidence suggests that use of high-dose combined oral contraceptives (OCs) (containing $>50 \mu \mathrm{g}$ of estrogen and $\geq 1 \mathrm{mg}$ progestin) places women at increased risk for periodontal diseases. Since the mid-1970s, OC formulations have dramatically changed. This study investigated the association between OC use and periodontal diseases among 4,930 National Health and Nutrition Examination Survey (NHANES) I and 5,001 NHANES III premenopausal U.S. women, aged 17 to 50 years, before and after the reduction of hormone levels in OCs.

Methods: Data for this cross-sectional study came from the first (NHANES I, 1971 to 1974) and third (NHANES III, 1988 to 1994) NHANES studies.

Results: The prevalence of OC use in the U.S. premenopausal female population in NHANES I was $22 \%$ and in NHANES III, $20 \%$. Using multivariable logistic regression, a protective association between current $\mathrm{OC}$ use and gingivitis was suggestive but not significant in both NHANES I (odds ratio [OR] $=0.65$; 95\% confidence interval [CI]: 0.42 to 1.01) and NHANES III (OR $=0.80$; 95\% CI: 0.61 to 1.02 ) surveys. Current OC use was also associated with a decreased risk of periodontal disease in NHANES I $(\mathrm{OR}=0.36 ; 95 \% \mathrm{CI}: 0.13$ to 0.96$)$ and a non-significant association in NHANES III (OR $=0.73 ; 95 \% \mathrm{CI}$ : 0.50 to 1.07 ).

Conclusion: This analysis failed to validate the theory that earlier high- or current low-dose OC use is associated with increased levels of gingivitis or periodontitis and suggests an important reexamination of the perceived association between $\mathrm{OC}$ use and periodontal diseases. J Periodontol 2005;76:1374-1385.

\section{KEY WORDS}

Contraceptives, oral/adverse effects; gingivitis/etiology; National Health and Nutrition Examination Survey III; periodontal diseases/epidemiology; periodontal diseases/etiology.

\footnotetext{
* Department of Periodontics, Prevention, and Geriatrics, University of Michigan Dental School, Ann Arbor, MI

$\dagger$ Department of Epidemiology, University of Michigan School of Public Health, Ann Arbor, MI.
}

$\mathrm{O}$ ral contraceptives (OCs) have been determined to be a safe, efficacious, and convenient form of contraception. ${ }^{1-5}$ However, hormonal contraceptive use by women of childbearing age has been suggested to place women at risk for periodontal diseases. ${ }^{6-10}$ Early small clinical studies of combined OCs containing high doses of estrogen (>50 $\mu \mathrm{g}$ of estrogen and $\geq 1 \mathrm{mg}$ progestin) found that these drugs increased the risk for gingival disease and suggested an adverse effect on the underlying supporting periodontal tissues. ${ }^{11-15}$ Other studies report that gingival inflammation increases in direct relationship with the duration of combined OC use. ${ }^{16,17}$ Limited animal studies also have lent support for these notions, suggesting that OCs have marked effects on the gingival microvasculature, altered capillary permeability, and cellular immune response seen in gingival diseases. ${ }^{18-21}$ As a result of these studies, the dental community has often attributed poor gingival health to the use of these steroid preparations in women who use OCs, although these data are now over 25 years old.

Since 1976, formulations of OCs have changed dramatically, resulting in brands that contain $<50 \mu \mathrm{g}$ estrogen and $\leq 1 \mathrm{mg}$ progestin. ${ }^{22-25}$ A more recent small clinical study indicated no association between low-dose OCs and gingivitis. ${ }^{26}$ However, the relationship 
between OCs and periodontal diseases using a large, population-based representative sample has not been investigated.

The current study expands on previous investigations conducted by using a subset of the sample of the U.S. population participating in the first and third National Health and Nutrition Examination Surveys (NHANES I and NHANES III). The purpose of this study was to evaluate the historically suggested association between "high-dose" OC use and periodontal diseases and to determine whether an association exists among users of the currently available "low-dose" OCs and periodontal conditions in females aged 17 to 50 years in the U.S. population.

\section{MATERIALS AND METHODS}

\section{Data Source}

Data for this study were obtained from NHANES I, conducted between 1971 and 1974 and NHANES III, conducted between 1988 and 1994. ${ }^{27,28}$ The NHANES surveys are cross-sectional studies designed to obtain information on the health and nutritional status of the non-institutionalized population of the United States conducted by the National Center for Health Statistics (NCHS). The sampling plan of each of the surveys followed a highly stratified multistage probability design in which a sample of the U.S. civilian, non-institutionalized population was selected to provide national estimates. Methods for the standardized interviews, dental examinations, and procedures for human protection and consent have been described elsewhere. ${ }^{29,30}$ While overall the surveys are meant to be similar, some differences between surveys are shown in Table 1 . The differences in the method of measuring periodontal conditions between the surveys did not allow for direct comparison. Furthermore, the number of records available for analysis varied depending on the variables used.

We limited the analyses to 4,930 (NHANES I) and 5,001 (NHANES III) non-pregnant, premenopausal women ages 17 to 50 years. A lower age boundary of 17 years was used to ensure that all individuals were eligible for data collection on contraception practices and the upper age boundary of 50 years to avoid issues related to misclassification effects due to postmenopausal hormonal therapy. Data were excluded for women who were pregnant, postmenopausal, or indicated the use of non-oral forms of contraception. In NHANES III, women reporting the use of a brand of OC that contained $>50 \mu \mathrm{g}$ of estrogen were excluded from the NHANES III analysis $(\mathrm{N}=4)$. Menopausal status was ascertained based on a respondent's report that her menstrual periods had not occurred within the last 12 months or stopped entirely (excluding women who were reported to be breastfeeding or pregnant).
Table I.

\section{Differences in the NHANES I and NHANES III Data Sets}

\begin{tabular}{|c|c|c|}
\hline $\begin{array}{l}\text { Dental } \\
\text { Examination }\end{array}$ & NHANES I & NHANES III \\
\hline $\begin{array}{l}\text { Periodontal } \\
\text { measures }\end{array}$ & $\begin{array}{l}\text { Periodontal } \\
\text { index (PI) }\end{array}$ & $\begin{array}{l}\text { Clinical } \\
\text { attachment (CAL) } \\
\text { Periodontal probing }\end{array}$ \\
\hline Gingivitis & PI & Bleeding on probing \\
\hline Calculus & $\mathrm{OHI}-\mathrm{S}$ & Calculus index \\
\hline Teeth examined & Full mouth & $\begin{array}{l}2 \text { diagonally opposite } \\
\text { quadrants }\end{array}$ \\
\hline $\begin{array}{l}\text { Oral health } \\
\text { behaviors }\end{array}$ & $\begin{array}{l}\text { Toothbrushing } \\
\text { frequency }\end{array}$ & None \\
\hline \multirow[t]{2}{*}{ OC measures } & $\begin{array}{l}\text { OC use in the last } \\
6 \text { months }(Y / N)\end{array}$ & OC use (ever/never) \\
\hline & $\begin{array}{l}\text { Are you still using } \\
\text { them now }(\mathrm{Y} / \mathrm{N})\end{array}$ & $\begin{array}{l}\text { Are you still using } \\
\text { them now }(Y / N) \\
\text { Age } O C \text { initiated } \\
\text { Duration of } O C \text { use } \\
\text { How many months } \\
\text { ago did you stop } \\
\text { taking } O C\end{array}$ \\
\hline $\begin{array}{l}\text { Tobacco } \\
\text { exposure }\end{array}$ & $\begin{array}{l}\text { Collected only for a } \\
\text { subgroup of the } \\
\text { 25- to } 74 \text {-year-old } \\
\text { sample }\end{array}$ & $\begin{array}{l}\text { Collected for } \\
\text { all individuals } \\
>12 \text { years }\end{array}$ \\
\hline $\begin{array}{l}\text { Time since last } \\
\text { dental visit }\end{array}$ & $\begin{array}{l}\text { Collected only for } \\
\text { a subgroup of the } \\
\text { 25- to 74-year-old } \\
\text { sample }\end{array}$ & $\begin{array}{l}\text { Collected for } \\
\text { all individuals } \\
>12 \text { years }\end{array}$ \\
\hline
\end{tabular}

\section{Clinical Examinations}

All dental examinations were conducted by trained and standardized examiners in dental units located in mobile examination centers (MEC). The periodontal status of individuals in NHANES I was assessed using the periodontal index $(\mathrm{PI}) .{ }^{31}$ The PI, a visual numeric index, assessed the degree of inflammation and the suspected presence of periodontal pockets around all teeth present in the mouth including third molars where zero indicated no disease, 1 = mild gingivitis, 2 = severe gingivitis, 6 = gingivitis with suspected pocket formation, and 8 advanced periodontal bone loss and loss of function. The presence of calculus was measured on six teeth using the simplified oral hygiene Index (OHI-S). NHANES III periodontal measures were conducted on randomly assigned half-mouths (one upper and one diagonally opposite lower quadrant) for each individual, excluding third molars. A periodontal probe was used to measure clinical attachment loss (CAL), probing 
depth (PD), gingival bleeding, and calculus on the buccal and mesial-buccal aspect of each tooth. ${ }^{30}$

\section{OC Use (Exposure to Sex Steroids)}

As noted in Table 1, OC use was assessed differently in the two NHANES surveys. Oral contraceptive use was assessed from the two interview questions in NHANES I "Have you taken birth control pills in the last 6 months?" and "Are you still taking them now?" Three categories for OC use were derived from these questions: current use, use within last 6 months, and non-current use. In NHANES III, OC use was derived from the two interview questions "Have you ever taken birth control pills for any reason?" and "How many months ago did you stop taking birth control pills or are you still taking them?"

In order to establish a definition of exposure (OC use) that could be compared between the two surveys, it was necessary to recode OC exposure in the NHANES III survey. This was achieved by creating the same categories of current use, use within the last 6 months, and non-current use to match the way the data were collected in the NHANES I. In both surveys, to attain the greatest contrast between the groups, any woman who had reported OC use in the last 6 months but was not currently using on the day of the NHANES examination was excluded from the analysis.

\section{Measurement of Periodontal Conditions}

Gingivitis. In NHANES I, gingivitis was defined as the presence of at least one tooth with a PI score of 1 or greater in the mouth. For NHANES III, the presence or absence of bleeding on probing at one or more sites was used to define gingivitis.

Periodontitis. The case definition for moderate periodontitis in NHANES I was defined as an individual with at least three teeth with a PI sore of 6 (gingivitis with pocket formation) or disease with pockets. ${ }^{32,33}$ For NHANES III, moderate periodontitis was defined as at least two sites with $4 \mathrm{~mm}$ of clinical attachment loss and a probing depth $\geq 4 \mathrm{~mm}$.

\section{Sociodemographic Covariates}

Sociodemographic, life indicators, and behavioral factors which have been shown to be associated with OC use were evaluated for confounding and effect modification. Variables obtained from the face-to-face interview included age, which was specified as both continuous and categorical, with three age categories (17 to 27 years, 28 to 37 years, and 38 to 50 years) in both surveys. Race was defined as black or white in both surveys. Hispanic ethnicity was not recorded in NHANES I and, therefore, could not be included in these analysis. Marital status was defined as married (married or living together as married), never married, or other. Education level was reported as $<12$ years of education,
12 years of education, or $>12$ years of education. Poverty income ratio is the ratio of reported family income category divided by the poverty income threshold. Using the recommended cutpoints for improved precision from the NHANES III Analytic Guidelines, ${ }^{34}$ three categories, low, medium, and high, were created for poverty index level in both data sets -0.00 to 1.350 , 1.351 to 3.500 , and $>3.501$. Parity was collected from the question "How many live births have you had?" Parity was coded as a categorical variable with categories being 0,1 to 2, $>3$ live births. Smoking status was defined as never smoked $(<100$ cigarettes in lifetime), former smoker (a positive answer to ever smoked but do not smoke cigarettes now), and current smoker (a positive answer to smoke now and have smoked $\geq 100$ cigarettes in a lifetime). Information on alcohol use and last dental visit was obtained by interview.

\section{Statistical Analysis}

The NHANES I and NHANES III surveys involve complex sampling designs; therefore, all statistical analyses were performed taking into account the effect of the study design as well as incorporating the examination sampling weights. The dependent variables of gingival inflammation and periodontitis were dichotomized and reported as present or absent. Initially, univariate statistics were calculated for all variables to describe the variables and their distributions along with measures of crude association (prevalence odds ratios $[\mathrm{OR}])$ between the outcomes (periodontitis, gingivitis) and other covariates of interest for the total sample in each survey. Measures of association were calculated using the chi square test of association. Tests of trend were performed using ordinary logistic regression and assigning ordinal scores for categories of age for both univariate and stratified analysis to investigate any trends in prevalence by age within $\mathrm{OC}$ groups in each survey. Potential confounding or effect modifying relationships between the covariates and the major outcomes were assessed using stratification and the comparison of the log-likelihood ratios of multivariable models with and without the interaction terms. Multivariable logistic regression analysis was conducted to assess the independent effect of OC use while controlling for all other covariates in each survey.

All analyses were conducted using a software package $^{\ddagger}$ which can account for complex sampling design and which gives adjusted variance estimations. Therefore, in all tables the number of participants per category is unweighted, while all means, percentages, and ORs are weighted to reflect the target population and standard errors and 95\% confidence intervals (CI) are adjusted for sampling design.

\footnotetext{
‡ STATA Statistics and Data Analysis, Version 6, STATA Corporation
} College Station, TX. 


\section{RESULTS}

There were 4,930 (NHANES I) and 5,001 (NHANES III) non-pregnant, premenopausal women aged 17 to 50 years with both interview and examination data available for analysis. Of these, 4,662 in NHANES I and 4,648 in NHANES III had at least six teeth and complete periodontal assessments. However, only 4,665 (NHANES I) and 4,510 (NHANES III) had complete data on OC use. The proportion of women who currently used OCs at the time of NHANES I (22.1\%) was slightly higher than at the time of NHANES III (20.0\%)
(Table 2). This represented approximately 10,057,478 and 843,963 , respectively, of the total number of women of child-bearing age in the United States at the time of each survey.

Both surveys showed that women who chose to use OCs were more likely to be younger than 33 years of age, white, non-smokers; less likely to have diabetes; more likely to have higher levels of education and income; have higher perceptions of their own oral health; and were more likely to participate in lifestyle behaviors such as moderate alcohol consumption and

Table 2.

Selected Characteristics of NHANES I and NHANES III Non-Pregnant, Premenopausal U.S. Women Aged 17 to 50 Years With and Without Periodontal Examinations

\begin{tabular}{|c|c|c|c|c|c|c|c|c|c|c|}
\hline \multirow[b]{3}{*}{ Characteristic } & \multicolumn{5}{|c|}{ NHANES I $(N=4,930)$} & \multicolumn{5}{|c|}{ NHANES III $(N=5,00 I)^{\ddagger}$} \\
\hline & \multicolumn{2}{|c|}{ With Exam } & \multicolumn{2}{|c|}{ Without Exam } & \multirow[b]{2}{*}{$P$ Value } & \multicolumn{2}{|c|}{ With Exam } & \multicolumn{2}{|c|}{ Without Exam } & \multirow[b]{2}{*}{$P$ Value } \\
\hline & $\mathrm{N}^{*}$ & $\% \dagger$ & $N^{*}$ & $\% \dagger$ & & $N^{*}$ & $\% \dagger$ & N* & $\% \dagger$ & \\
\hline Age (years; SE) & 4,662 & $30.0(0.22)$ & 268 & $39.2(0.45)$ & 0.01 & 4,648 & $32.0(0.12)$ & 240 & $34.9(0.62)$ & 0.01 \\
\hline \multicolumn{11}{|l|}{ OC use } \\
\hline Current & 1,106 & 22.1 & 42 & 15.7 & & 842 & 20.4 & 20 & 6.1 & \\
\hline Past & 252 & 5.3 & 13 & 3.8 & & 2,488 & 58.4 & 195 & 66.6 & \\
\hline Never & 3,307 & 72.6 & 204 & 80.5 & 0.01 & 1,180 & 21.5 & 91 & 27.2 & 0.01 \\
\hline \multicolumn{11}{|l|}{ Race } \\
\hline White & 3,709 & 87.5 & 217 & 92.2 & & 2,832 & 81.2 & 150 & 78.4 & \\
\hline Black & 892 & 11.3 & 38 & 7.3 & 0.07 & 1,630 & 13.8 & 83 & 12.8 & 0.26 \\
\hline \multicolumn{11}{|l|}{ Marital Status } \\
\hline Married & 3,086 & 65.6 & 201 & 81.3 & & 2,502 & 59.6 & 116 & 60.6 & \\
\hline Single & 1,059 & 25.1 & 15 & 5.2 & & 1,462 & 26.8 & 72 & 21.9 & \\
\hline Other & 524 & 9.3 & 42 & 13.3 & 0.01 & 676 & 13.6 & 51 & 17.6 & 0.08 \\
\hline \multicolumn{11}{|l|}{ Education } \\
\hline$<12$ years & $|, 25|$ & 22.6 & 130 & 43.2 & & 1,468 & 19.0 & 106 & 28.3 & \\
\hline 12 years & 2,008 & 46.0 & 107 & 48.2 & & 1,676 & 35.6 & 85 & 45.4 & \\
\hline$>12$ years & 1,368 & 31.4 & 21 & 8.6 & 0.01 & $|, 48|$ & 45.4 & 48 & 26.3 & 0.01 \\
\hline \multicolumn{11}{|l|}{ Income Level } \\
\hline Low & 1,210 & 21.0 & 75 & 20.7 & & 1,678 & 22.2 & 95 & 27.9 & \\
\hline Middle & 1,919 & 50.3 & 125 & 43.3 & & I,457 & 34.3 & 72 & 49.2 & \\
\hline High & ।,382 & 28.7 & 54 & 36.0 & 0.05 & 1,125 & 43.5 & 41 & 22.9 & 0.01 \\
\hline \multicolumn{11}{|l|}{ Smoking } \\
\hline Current & 260 & 36.3 & 35 & 59.1 & & 1,089 & 27.9 & 91 & 43.5 & \\
\hline Past & 97 & 13.5 & 8 & 14.8 & & 515 & 14.3 & 31 & 14.8 & \\
\hline Never & 360 & 50.2 & 18 & 26.1 & 0.01 & 3,044 & 57.7 & 118 & 41.6 & 0.01 \\
\hline \multicolumn{11}{|l|}{ Parity } \\
\hline 0 & 1,260 & 31.2 & 20 & 8.9 & & 1,325 & 35.0 & 40 & 23.4 & \\
\hline |-2 & 890 & 18.2 & 33 & 12.4 & & $|, 98|$ & 45.6 & 79 & 39.2 & \\
\hline$\geq 3$ & 2,513 & 50.7 & 209 & 78.8 & 0.01 & 1,228 & 19.4 & 80 & 37.4 & 0.01 \\
\hline
\end{tabular}

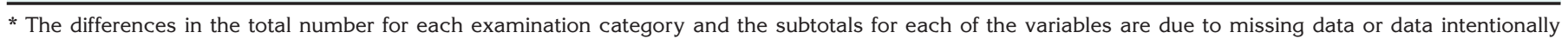
collected due to study design.

$\dagger$ Weighted percentage.

$\neq$ Women were excluded who had partial periodontal examinations, $N=113$. 
utilizing dental care more frequently (unpublished data). The potential bias introduced by non-participation in the dental examinations in both surveys is shown in Table 2. In both NHANES I and NHANES III there were some statistically significant differences among women with periodontal examinations and those without periodontal examinations. The women with periodontal examinations were significantly younger and more likely to use OCs, have higher levels of education, to be non-smokers, and have children compared to women without periodontal examinations.

\section{Periodontal Characteristics}

Table 3 presents the periodontal conditions for premenopausal adult U.S. women, 17 to 50 years of age, stratified by OC use. Gingivitis and calculus were common among women in both surveys. The mean age was 30.0 (SE 0.22) years in NHANES 1 and 32.0 (SE 0.12) years in NHANES III. The mean number of teeth present was slightly higher in NHANES III (26.5; SE 0.09) than in NHANES I (25.4; SE 0.11). Using the case definition in this study, the overall prevalence of moderate periodontitis in the NHANES I population was $13.1 \%$ and $10.7 \%$ in the NHANES III population.
When comparing women by history of OC use, women who reported current use were significantly younger $(P<0.01)$ than women who reported non-current use in both surveys. No significant differences were found in the prevalence of gingivitis or calculus between current or non-current users in both surveys (Table 3). Current OC users had a significantly lower prevalence of periodontitis than non-current users ( $8.9 \%$ versus $13.3 \%, P<0.01)$ and $(4.4 \%$ versus $12.5 \%$, $P<0.01)$ as well as less tooth loss in both surveys. Moreover, current OC users in NHANES III had a lower mean CAL as well as lower mean probing depth than non-current users.

\section{Prevalence of Periodontal Conditions}

There were no significant differences in the prevalence of gingivitis between current $\mathrm{OC}$ users and non-current users after stratifying for individual risk indicators such as age, marital status, race, educational level, income level, smoking status, number of births, time since last dental cleaning, self-perception of oral and general health, presence of insurance, and alcohol use for either NHANES surveys (data not shown).

Table 4 shows the prevalence of moderate periodontitis within selected demographic variables stratified by OC use. Overall, current OC users showed a

\section{Table 3.}

\section{Periodontal Characteristics of Non-Pregnant, Pre-Menopausal U.S. Women Aged 17 to 50 Years by OC Exposure}

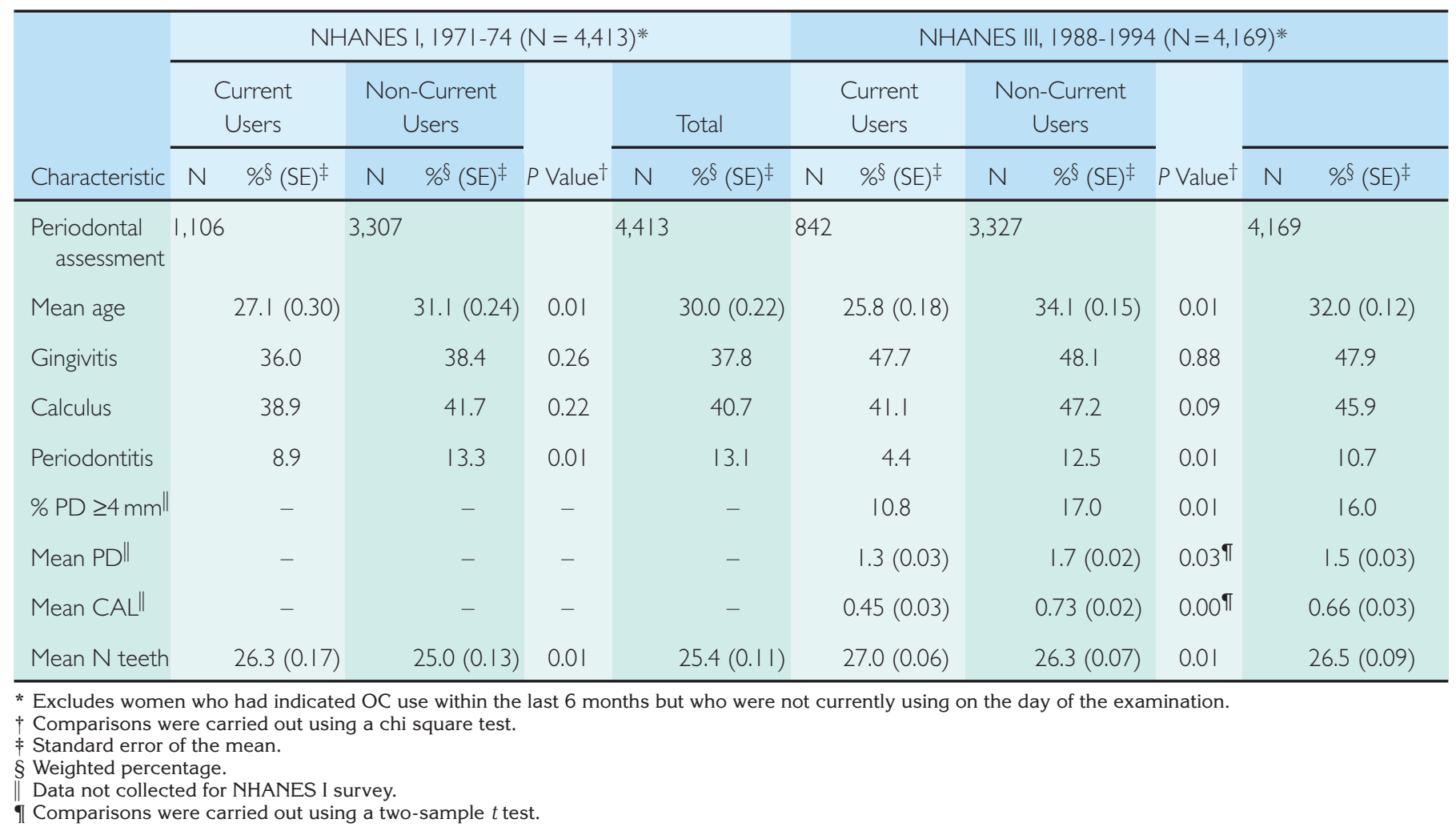


Table 4.

Prevalence of Periodontitis for Selected Covariates Stratified by OC Use Among Non-Pregnant, Premenopausal U.S. Women Aged 17 to 50 Years: NHANES I and III

\begin{tabular}{|c|c|c|c|c|c|c|c|c|c|c|c|c|}
\hline \multirow[b]{3}{*}{ Covariate } & \multirow[b]{3}{*}{ Total N } & \multirow{2}{*}{\multicolumn{2}{|c|}{$\begin{array}{c}\begin{array}{c}\text { Current } \\
\text { Users }\end{array} \\
(\mathrm{N}=1,106) \\
\text { Prevalence }\end{array}$}} & \multirow{2}{*}{\multicolumn{2}{|c|}{$\begin{array}{c}\begin{array}{c}\text { Non-Current } \\
\text { Users }\end{array} \\
(\mathrm{N}=3,307) \\
\text { Prevalence }\end{array}$}} & \multirow[b]{3}{*}{$P$ Value* } & \multirow[b]{3}{*}{ Total N } & \multirow{2}{*}{\multicolumn{2}{|c|}{$\begin{array}{c}\begin{array}{c}\text { Current } \\
\text { Users } \\
(\mathrm{N}=842)\end{array} \\
\text { Prevalence }\end{array}$}} & \multirow{2}{*}{\multicolumn{2}{|c|}{$\begin{array}{c}\text { Non-Current } \\
\text { Users } \\
(\mathrm{N}=3,327) \\
\text { Prevalence }\end{array}$}} & \multirow[b]{3}{*}{$P$ Value* } \\
\hline & & & & & & & & & & & & \\
\hline & & $N$ & $\%{ }^{\dagger}$ & $\mathrm{N}$ & $\%^{\dagger}$ & & & $N$ & $\% \dagger$ & $\mathrm{N}$ & $\%^{\dagger}$ & \\
\hline Overall prevalence & & & 8.9 & & 13.1 & 0.02 & & & 4.4 & & 12.5 & 0.01 \\
\hline $\begin{array}{l}\text { Age (years) } \\
17-27 \\
28-37 \\
38-50\end{array}$ & $\begin{array}{l}1,641 \\
1,739 \\
1,033\end{array}$ & $\begin{array}{r}583 \\
424 \\
99\end{array}$ & $\begin{array}{r}5.4 \\
6.4 \\
14.3\end{array}$ & $\begin{array}{r}1,058 \\
1,315 \\
934\end{array}$ & $\begin{array}{r}3.9 \\
11.0 \\
19.1\end{array}$ & $0.01 \ddagger$ & $\begin{array}{l}1,521 \\
1,430 \\
1,218\end{array}$ & $\begin{array}{r}559 \\
256 \\
27\end{array}$ & $\begin{array}{r}2.6 \\
11.3 \\
5.3\end{array}$ & $\begin{array}{r}962 \\
1,174 \\
1,191\end{array}$ & $\begin{array}{r}3.7 \\
13.2 \\
22.1\end{array}$ & $0.01^{\ddagger}$ \\
\hline $\begin{array}{l}\text { Race } \\
\text { White } \\
\text { Black }\end{array}$ & $\begin{array}{r}3,507 \\
911\end{array}$ & $\begin{array}{l}891 \\
215\end{array}$ & $\begin{array}{r}6.1 \\
10.8\end{array}$ & $\begin{array}{r}2,613 \\
694\end{array}$ & $\begin{array}{r}9.7 \\
19.3\end{array}$ & 0.01 & $\begin{array}{l}2,548 \\
1,620\end{array}$ & $\begin{array}{l}551 \\
291\end{array}$ & $\begin{array}{l}4.0 \\
6.8\end{array}$ & $\begin{array}{l}1,997 \\
1,329\end{array}$ & $\begin{array}{l}11.4 \\
17.1\end{array}$ & 0.01 \\
\hline $\begin{array}{l}\text { Marital Status } \\
\text { Married } \\
\text { Single } \\
\text { Other }\end{array}$ & $\begin{array}{r}2,893 \\
1,019 \\
499\end{array}$ & $\begin{array}{l}788 \\
198 \\
120\end{array}$ & $\begin{array}{r}6.0 \\
3.4 \\
\mid 4.6\end{array}$ & $\begin{array}{r}2,105 \\
821 \\
379\end{array}$ & $\begin{array}{r}12.3 \\
4.2 \\
24.7\end{array}$ & 0.01 & $\begin{array}{r}2,273 \\
1,276 \\
612\end{array}$ & $\begin{array}{r}418 \\
340 \\
84\end{array}$ & $\begin{array}{r}4.9 \\
1.9 \\
12.3\end{array}$ & $\begin{array}{r}1,855 \\
936 \\
528\end{array}$ & $\begin{array}{r}13.2 \\
5.4 \\
20.9\end{array}$ & 0.01 \\
\hline $\begin{array}{l}\text { Education } \\
<12 \text { years } \\
12 \text { years } \\
>12 \text { years }\end{array}$ & $\begin{array}{l}1,191 \\
1,958 \\
1,244\end{array}$ & $\begin{array}{l}225 \\
510 \\
368\end{array}$ & $\begin{array}{r}13.4 \\
5.8 \\
4.5\end{array}$ & $\begin{array}{r}963 \\
1,446 \\
876\end{array}$ & $\begin{array}{r}19.8 \\
10.0 \\
5.0\end{array}$ & 0.02 & $\begin{array}{l}1,324 \\
1,497 \\
1,327\end{array}$ & $\begin{array}{l}219 \\
312 \\
307\end{array}$ & $\begin{array}{r}10.7 \\
4.5 \\
2.6\end{array}$ & $\begin{array}{l}1,105 \\
1,185 \\
1,020\end{array}$ & $\begin{array}{r}17.4 \\
16.3 \\
7.4\end{array}$ & 0.08 \\
\hline $\begin{array}{l}\text { Poverty index level } \\
0-1.35 \\
1.351-3.500 \\
\geq 3.501\end{array}$ & $\begin{array}{r}1,116 \\
2,165 \\
990\end{array}$ & $\begin{array}{l}255 \\
549 \\
265\end{array}$ & $\begin{array}{r}11.6 \\
8.5 \\
2.5\end{array}$ & $\begin{array}{r}859 \\
1,613 \\
725\end{array}$ & $\begin{array}{r}15.6 \\
11.7 \\
7.3\end{array}$ & 0.01 & $\begin{array}{r}762 \\
1,624 \\
1,455\end{array}$ & $\begin{array}{l}174 \\
320 \\
283\end{array}$ & $\begin{array}{r}10.5 \\
5.0 \\
1.7\end{array}$ & $\begin{array}{r}588 \\
1,304 \\
1,172\end{array}$ & $\begin{array}{r}16.9 \\
13.3 \\
9.6\end{array}$ & 0.01 \\
\hline $\begin{array}{l}\text { Smoking status§ } \\
\text { Current } \\
\text { Past } \\
\text { Never }\end{array}$ & $\begin{array}{r}243 \\
94 \\
343\end{array}$ & $\begin{array}{l}53 \\
17 \\
58\end{array}$ & $\begin{array}{c}21.5 \\
0.011 \\
5.2\end{array}$ & $\begin{array}{r}190 \\
77 \\
284\end{array}$ & $\begin{array}{l}25.9 \\
12.6 \\
14.8\end{array}$ & 0.01 & $\begin{array}{r}978 \\
470 \\
2,721\end{array}$ & $\begin{array}{r}175 \\
84 \\
583\end{array}$ & $\begin{array}{l}8.0 \\
3.6 \\
3.2\end{array}$ & $\begin{array}{r}803 \\
386 \\
2,138\end{array}$ & $\begin{array}{r}21.5 \\
11.9 \\
8.2\end{array}$ & 0.01 \\
\hline $\begin{array}{l}\text { Last dental visit } \$ \\
\leq 2 \text { years ago } \\
>2 \text { years ago }\end{array}$ & $\begin{array}{l}408 \\
149\end{array}$ & $\begin{array}{l}95 \\
19\end{array}$ & $\begin{array}{r}7.5 \\
15.8\end{array}$ & $\begin{array}{l}313 \\
138\end{array}$ & $\begin{array}{l}10.4 \\
28.2\end{array}$ & 0.01 & $\begin{array}{l}1,956 \\
2,059\end{array}$ & $\begin{array}{l}434 \\
374\end{array}$ & $\begin{array}{l}2.8 \\
7.3\end{array}$ & $\begin{array}{l}1,522 \\
1,685\end{array}$ & $\begin{array}{r}8.5 \\
18.4\end{array}$ & 0.01 \\
\hline $\begin{array}{l}\text { Alcohol use } \\
\text { Yes } \\
\text { No }\end{array}$ & $\begin{array}{r}3,412 \\
9,95\end{array}$ & $\begin{array}{l}938 \\
168\end{array}$ & $\begin{array}{l}6.6 \\
7.4\end{array}$ & $\begin{array}{r}2,480 \\
827\end{array}$ & $\begin{array}{r}9.9 \\
13.9\end{array}$ & 0.01 & $\begin{array}{l}3,093 \\
1,074\end{array}$ & $\begin{array}{l}637 \\
205\end{array}$ & $\begin{array}{l}4.0 \\
7.0\end{array}$ & $\begin{array}{r}2,456 \\
869\end{array}$ & $\begin{array}{l}12.6 \\
12.3\end{array}$ & 0.01 \\
\hline $\begin{array}{l}\text { Parity } \\
0 \\
1-2 \\
\geq 3\end{array}$ & $\begin{array}{r}1,214 \\
820 \\
2,389\end{array}$ & $\begin{array}{l}295 \\
287 \\
524\end{array}$ & $\begin{array}{r}3.0 \\
4.6 \\
10.3\end{array}$ & $\begin{array}{r}909 \\
523 \\
1,864\end{array}$ & $\begin{array}{r}4.1 \\
11.1 \\
15.0\end{array}$ & $0.00^{\ddagger}$ & $\begin{array}{l}1,200 \\
1,793 \\
1,174\end{array}$ & $\begin{array}{l}342 \\
400 \\
100\end{array}$ & $\begin{array}{r}1.1 \\
8.4 \\
14.7\end{array}$ & $\begin{array}{r}858 \\
1,393 \\
1,074\end{array}$ & $\begin{array}{r}5.4 \\
13.1 \\
20.1\end{array}$ & $0.00^{\prime}$ \\
\hline
\end{tabular}

* P values for Cochran-Mantel-Haenszel chi-square test of association between OC groups.

$\dagger$ Weighted percentage.

$\ddagger$ Tests of trend were performed using ordinary logistic regression and assigning ordinal scores for categories of age and parity; significance set at $P<0.05$.

$\S$ The variables smoking status and time since last dental visit were collected for only a subgroup of individuals in the NHANES I survey.

|| Small number of observations in cell.

consistent pattern of having a lower prevalence of periodontitis compared to non-current users. The prevalence of periodontitis increased with age, with non- current users demonstrating greater incremental increases in prevalence in each succeeding age group. Overall, the prevalence of periodontitis exhibited 
significantly increasing trends across age groups, younger to older. Despite a large number of current OC users having missing data for smoking exposure in NHANES I, due to this variable being collected only for a subgroup of the sample, we still observed the expected association of an increased prevalence of periodontitis among current smokers compared to never smokers in both groups. The fact that current OC users in NHANES III were, on average, 8 years younger than women who were classified non-current users may account for the consistent pattern of lower prevalence of moderate periodontal disease among current users.

We assessed the possibility that the relation between OC use and prevalence of periodontitis was modified by age or smoking. In NHANES I, there was a marginally significant interaction between current $\mathrm{OC}$ use and periodontitis in the middle age group of women (28 to 37 years) who were current OC users $(P=0.043)$. Although there was a consistent pattern of reduced prevalence of periodontitis among current OC users compared to non-current users in NHANES III, it appeared that there was a greatly reduced risk of periodontitis among the oldest age group of current $O C$ users. The results of the stratified analysis were not significant and it was determined that this apparent reduced risk was the result of the small number of users among the oldest age group, rather than heterogeneity within the groups. Interactions between smoking status and OC use were not statistically significant in either NHANES survey, but the NHANES I analyses had low power to detect interactions due to the small number of subjects for whom smoking data were collected.

\section{Multiple Regression Modeling}

Separate multiple variable logistic regression models were fit to examine the association of $\mathrm{OC}$ use and periodontal conditions of women using high-dose OCs compared to women not using OCs (NHANES I) and women using low-dose OCs compared to women not using OCs (NHANES III). All models were adjusted for age, race, education level, poverty index level, marital status, alcohol consumption, presence of calculus, and parity. Smoking status and time since last dental visit data were not collected for the entire sample in the NHANES I survey. Therefore, only NHANES III models were adjusted for these variables. Variables were retained in the final models if they were statistically significant at the 0.05 level or if their removal caused a $5 \%$ or more change in the odds ratio for the periodontal condition of interest.

\section{NHANES I (High-Dose OC)}

Gingivitis model. Unadjusted for confounding variables, current OC use was associated with a $24 \%$ lower prevalence of gingivitis when compared with non-current OC use among premenopausal women ages 17 to 50 years (OR $=0.76 ; 95 \% \mathrm{CI}$ : 0.42 to 0.98 ) (Table 5). After adjustment for confounding variables and sampling design, current $\mathrm{OC}$ use still suggested a protective association (OR $=0.65$; $95 \% \mathrm{CI}$ : 0.42 to 1.01 ), although this association did not reach statistical significance. Factors that remained significantly associated with the prevalence of gingivitis (data not shown) were older age, lower levels of education (not having graduated from high school), lower poverty index level, presence of dental calculus, and higher parity.

Periodontitis model. There was a significant protective association between current $\mathrm{OC}$ use and moderate periodontitis ( $\mathrm{OR}=0.58 ; 95 \% \mathrm{CI}: 0.45$ to 0.77 ) in the unadjusted analysis (Table 5). When the data were further adjusted for all significant factors from the bivariate analysis, OC use was associated with slightly decreased odds of periodontitis ( $\mathrm{OR}=0.36$; 95\% CI: 0.13 to 0.96 ). Increased age, being previously married, lower poverty index level, having less than a high school education, and presence of dental calculus were variables associated with increased odds of periodontitis (data not shown).

\section{NHANES III (Low-Dose OC)}

Gingivitis model. Similar to NHANES I, the crude or unadjusted odds ratio showed a protective association between gingivitis and current $\mathrm{OC}$ use when compared with non-current use $(\mathrm{OR}=0.82 ; 95 \% \mathrm{CI}$ : 0.68 to 0.97). Current OC use was associated with a slightly,
Table 5.

\section{Final Logistic Regression Models of the Association Between Oral Contraceptive Use and Periodontal Diseases, Controlling for Selected Variables, Among Premenopausal Women Aged 17 to 50 Years}

\begin{tabular}{lccc|c}
\hline & \multicolumn{2}{c}{ NHANES I N $=4,4 \mid 3$} & \multicolumn{2}{c}{ NHANES III N $=4,169$} \\
\cline { 2 - 5 } Periodontal & Crude & Adjusted & Crude & Adjusted \\
Status & $\mathrm{OR}(\mathrm{Cl})$ & $\mathrm{OR}(\mathrm{Cl})$ & $\mathrm{OR}(\mathrm{Cl})$ & $\mathrm{OR}(\mathrm{Cl})$ \\
\hline Gingivitis & $\mathrm{OR}=0.76$ & $\mathrm{OR}=0.65^{*}$ & $\mathrm{OR}=0.82$ & $\mathrm{OR}=0.80^{\dagger}$ \\
& $(0.42-0.98)$ & $(0.42-1.01)$ & $(0.68-0.97)$ & $(0.61-1.02)$ \\
Periodontitis & $\mathrm{OR}=0.58$ & $\mathrm{OR}=0.36^{\ddagger}$ & $\mathrm{OR}=0.32$ & $\mathrm{OR}=0.73 \S$ \\
& $(0.45-0.77)$ & $(0.13-0.96)$ & $(0.23-0.45)$ & $(0.50-1.07)$ \\
\hline
\end{tabular}

* Model adjusted for OC use, age, race, marital status, poverty index level, education level, presence of calculus, alcohol use, and parity.

$\dagger$ Model adjusted for OC use, age, race, marital status, poverty index level, education level, presence of calculus, alcohol use, and smoking status.

\# Model adjusted for OC use, age, marital status, poverty index level, education level, presence of calculus, alcohol use, and parity.

$\S$ Model adjusted for OC use, age, marital status, race, poverty index level, education level, presence of calculus, smoking status, alcohol use, and time since last dental visit. 
but not statistically significant, lower prevalence of gingivitis (OR $=0.80 ; 95 \% \mathrm{CI}$ : 0.61 to 1.02 ) when adjusted for similar covariates (data not shown) as in the NHANES I gingivitis model (Table 5). However, unlike the NHANES I model, increasing age in NHANES III significantly decreased the odds of having gingivitis. Also, current smokers showed a significantly decreased likelihood of having gingivitis compared to never smokers.

Periodontitis model. The crude model estimated a significant association between current use of OCs and decreased probability of having periodontitis $(\mathrm{OR}=$ $0.32 ; 95 \% \mathrm{CI}: 0.23$ to 0.77 ). Adjustment with the covariates in the final model virtually eliminated the apparent protective effect of OC seen with the crude OR model (OR $=0.73 ; 95 \% \mathrm{CI}: 0.50$ to 1.07 ) (Table 5). Of the covariables in the model (data not shown), increasing age, being non-white, current smoker, presence of calculus, having a high school or less education, and being among the lowest poverty index level significantly increased the probability of having periodontitis.

\section{DISCUSSION}

The controversy over the safety of OCs has been the topic of much debate. The suspicion that high-dose OCs were associated with an increased risk of thrombotic events prompted a dramatic decrease in estrogen content from $>100 \mu \mathrm{g}$ of ethinyl estradiol to 20 to $50 \mu \mathrm{g}$ in current formulations soon after these preparations were introduced onto the market. ${ }^{35}$ Moreover, the debate on the effects of OC use and periodontal diseases has drawn heavily from studies that report an increase in gingival inflammation related to hormone changes during pregnancy ${ }^{36-39}$ as well as small clinical studies evaluating high-dose OCs. ${ }^{11-13}$ Today, for most healthy women, OC use is considered to be a safe, convenient, and effective method of contraception. Yet, current thinking still suggests that low-dose $\mathrm{OC}$ use potentiates gingival or periodontal diseases as reflected in the recent consensus report related to periodontal diagnosis from a workshop held in 1999 by the American Academy of Periodontology recommending the classification of "OC induced gingivitis," 40 despite the fact that these data came from small trials which are over 25 years old.

The aim of this study was to examine the relationship between OC use and gingivitis and periodontitis in premenopausal women, using large populationbased representative samples. It was anticipated that the OC users in NHANES I would have a higher prevalence of gingival inflammation and poorer periodontal health than non-OC users resulting from the higher doses of estrogen and progestins of the high-dose (>50 $\mu$ g estrogen) OC pills of the early 1970s. In addi- tion, we anticipated that women using the modern low-dose OC pills available at the time of NHANES III would exhibit an increased, yet less marked, prevalence of gingivitis and periodontitis than those not using OCs.

In NHANES I, a negative association (protective) between current $\mathrm{OC}$ use and gingivitis was suggested after controlling for all potential confounding variables including age, but failed to reach the significance level of $P<0.05(P=0.057)$. These results were unexpected based on earlier reports that demonstrated an increase in gingival inflammation among users of OC. ${ }^{12-14}$

Using the gingival index (GI) to assess gingival inflammation, El-Ashiry et al. ${ }^{12}$ reported significantly increased gingival inflammation among young women who had used sex steroid contraceptives when compared to women of similar ages who had not used OC. Another cross-sectional study conducted by Kalkwarf ${ }^{13}$ demonstrated that the women using OCs had more gingivitis independent of dental plaque scores; however, this study has been criticized for the study design and sample size deficiencies. ${ }^{6}$ In addition, studies that used the GI to measure gingivitis indicated that gingival inflammation increases in direct relationship with the duration of OC use. ${ }^{16,17}$

Direct comparisons of our study with these previous studies examining the relationship of gingival conditions and $O C$ use are difficult, as different methods were used to measure disease. The earlier studies used the GI to assess gingival inflammation, while the PI was used in NHANES I. The GI combines both a visual and a periodontal probe assessment to measure the severity of the gingival lesion, whereas the PI employs only a visual assessment. The PI has been criticized as being subjective and less accurate than the GI since it does not take into account the clinical distinction between health and various levels of severity. ${ }^{41}$ As such, the difference in our results may be related to use of different measurement methods.

According to our results, modern low-dose OC use did not increase the prevalence of gingivitis. As in NHANES I, OC use was not associated with increased prevalence of gingivitis. Interestingly, again, a nonsignificant protective association was seen. In addition, when comparing the multivariable models, the magnitude of the effect of OC use on gingivitis between the NHANES I and III surveys was roughly equal.

A review of a recent clinical study investigating low-dose OCs lends support to our findings. ${ }^{42}$ Preshaw and colleagues demonstrated, using a prospective, split-mouth, experimental gingivitis model in 30 premenopausal women, that low-dose OC formulations failed to intensify gingival disease after evaluating mean plaque index, gingival index, or gingival crevicular fluid volumes. These findings, in keeping 
with ours, resulted in the authors concluding that lowdose OC formulations do not influence the inflammatory response of the gingival tissues to dental plaque. ${ }^{42}$ Conversely, in a clinical study by Tilakaratne et al., ${ }^{43}$ which examined the effect of OCs and injectable progestin-only contraceptives on periodontal conditions, found that women who used hormonal contraceptives for $<2$ years showed higher mean GI scores than non-users. However, the Tilakaratne et al. study did not differentiate between participants using OCs or injectable progestin-only hormones. As Preshaw and colleagues point out, ${ }^{42}$ this is of potential importance because the daily dose of progestin from the progestin-only injectable method is estimated to be 10 times higher than the dose of progestin found in the $\mathrm{OC}$ formulation used in the Tilakaratne et al. study.

In both NHANES I and NHANES III a relatively strong protective association was seen between periodontitis and current $\mathrm{OC}$ use, using univariate analysis $(\mathrm{OR}=0.58 ; 95 \% \mathrm{CI}: 0.45$ to 0.77$)$ and $(\mathrm{OR}=0.32$; 95\% CI: 0.23 to 0.45 ), respectively. However, no statistically significant relationship was seen in the NHANES I analysis after adjusting for potential confounders. The lack of an association between OC use and periodontitis shown in our analysis supports a previous study by Pankhurst et al. ${ }^{16}$ which detected no change in the periodontal attachment levels in women taking oral contraceptives compared to controls. In contrast, Knight and Wade reported a significant loss of attachment in women using oral contraceptives for over 18 months, although there were no differences in gingival inflammation between OC users and non-users. ${ }^{17}$ Possible explanations for the inconsistency between our findings and the Knight and Wade study are differences in measurement of periodontal disease, sample sizes, selection bias, or greater examiner variation. Furthermore, our analysis evaluates current $\mathrm{OC}$ use and does not differentiate by duration of use.

A possible reason for the absence of a significant finding in our analysis for modern low-dose oral contraceptives may lie in the way OC exposure was defined for the analysis of the NHANES III data. As mentioned before, the exposure questions were different in each survey. Our recategorization of OC use in NHANES III resulted in approximately 2,148 women who had a history of past exposure to OCs (some of whom had up to 20 years of exposure) being placed into the "non-current use" group. In an effort to make the OC data comparable between the surveys, there may have been some misclassification of the outcomes, resulting in the dilution of the association between $\mathrm{OC}$ use and periodontal disease.

To determine if the recategorization of OC use affected the outcome, subsequent analysis excluding women who indicated a prior use in NHANES III was generated. The deletion of former users from the noncurrent use group did not appreciably change the reported odds ratios ( $\mathrm{OR}=0.57 ; 95 \% \mathrm{Cl}$ : 0.38 to 0.95 ).

In addition, the absence of significant findings may be due to the different methods used to assess periodontal disease. Although it appears that there was a decline in the prevalence of periodontitis between the time that the NHANES I and NHANES III surveys were performed (13.1\% versus $10.7 \%$ ), these discrepancies may be attributed to differences in the clinical methods of disease assessment. In NHANES I, the assumptions related to periodontal disease progression and the use of the subjective PI may have accounted for an inflated estimate of periodontitis relative to the NHANES III findings. Likewise, in the NHANES III data collection, split-mouth examinations may have similarly underestimated the prevalence of disease. ${ }^{44}$

Although other analyses have suggested no change in gingivitis in the United States over recent years, ${ }^{45}$ our study identified an increase of $10 \%$ in the prevalence of gingivitis between NHANES I and NHANES III among premenopausal women. It is quite possible that the use of the PI, which gives greater weight to advanced disease, may have actually underreported gingivitis. Therefore, the increase in gingivitis we observed is most likely an artifact of the clinical methods employed. We found that, while slightly higher, our estimates were similar to those reported by Albandar and Kingman for prevalence of gingival bleeding (gingivitis) for women between the ages of 30 to 39 and 40 to 49 years in a NHANES III analysis. ${ }^{45}$

In the analysis of the NHANES I population, the association between periodontitis and $\mathrm{OC}$ use depended on age. It appears that the protection derived from current OC use may be particularly beneficial with increasing age. How might age modify the effects exerted by OC use? First, prior use of high-dose OCs (>50 $\mu \mathrm{g}$ of estrogen) may have enhanced the development of the attachment apparatus (e.g., bone mass, periodontal ligament), such that when these same women were at greatest risk for bone loss, it would appear that OC use was protective. To our knowledge, evidence for the association of exogenous estrogen use for maintaining periodontal tissues among premenopausal women is lacking, but estrogen supplementation has been reported to be associated with improved gingival health and reduced attachment loss in post-menopausal women. ${ }^{46,47}$ However, age did not appear to modify the association between current OC use and prevalence of periodontitis in the older age groups in the NHANES III survey. The small number of current $\mathrm{OC}$ users among the older age groups may have reduced our ability to detect an interaction between age and $\mathrm{OC}$ use. An alternative possibility is 
that women who were former users may have discontinued pill use due to periodontal disease or other problems associated with high-dose OC use, leaving relatively healthier women. Thus, when compared with non-current users, the lower prevalence of periodontitis among older current $O C$ users may be the result of survivor bias. Perhaps most likely is that behaviors associated with OC use are protective, and this relationship is best demonstrated in women who are at greatest risk in our study for periodontal disease those who are older. The patterns in the data consistent with this interpretation only reached statistical significance in the middle age range where sufficient numbers of women at risk for periodontal disease were also taking OCs.

Our findings that $\mathrm{OC}$ use may be protective for users are of considerable interest. OC use may represent a proxy for health or lifestyle behaviors that may be associated with higher levels of income and better periodontal health. Studies have suggested that women who use OCs or hormone replacement therapy (HRT) may differ from women who do not in terms of more favorable lifestyles, higher education and income levels, and health awareness. ${ }^{48-50}$

If the women in our study who used OCs had lower overall risk profiles for periodontal diseases; i.e., were healthier, had better oral health behaviors, and had greater access to and use of dental care than nonusers, healthy user bias might explain some of the reduced risk of periodontal disease we observed in OC users. Unfortunately, direct measures of individual oral hygiene behavior were not made in the NHANES III survey. Using date of last dental visit as a proxy for oral hygiene status, more of the current OC users than non-current users reported visiting a dentist within the last 2 years. However, those who were current OC users were also more likely to have smoked (NHANES I) and consumed alcohol, suggesting an increased risk of periodontitis (data not shown). Yet the possibility remains that the putative protective effect of $\mathrm{OC}$ use on periodontal diseases that we observed in this study may be spurious and a consequence of healthier lifestyles resulting from a healthy woman bias. The inherent risk of healthy user bias in observational studies, even after adjusting for a wide range of covariates, was most recently demonstrated when the surprising results of the Women's Health Initiative (WHI) Postmenopausal Hormone Therapy Trial were released and the estrogen plus progestin component of the study was prematurely halted. The risk of coronary heart disease, breast cancer, and stroke increased in women assigned treatment of estrogen plus progestin. ${ }^{51}$ Observational studies of HRT had found consistent protection against heart disease; ${ }^{52-54}$ this now appears due to strong selection and healthy user biases. ${ }^{55,56}$ Women using
HRT in observational studies were healthier than those not using HRT in an amount not fully correctable by statistically controlling with available covariates, distorting the true overall risk-benefit ratio of using HRT for prevention of heart disease.

The results of our analysis did not substantiate the previous theory that high-dose OC use is associated with gingivitis or periodontitis. Furthermore, the present findings suggest that there may be no detrimental association between modern low-dose OC use and periodontal diseases for the majority of women who use these products. While it is premature to make definitive statements regarding a protective cause-and-effect relationship between $\mathrm{OC}$ use and periodontal conditions due to the cross-sectional nature of the data, these findings suggest an important reexamination of the perceived relationship between $\mathrm{OC}$ use and periodontal diseases.

Further studies are needed to clarify the role of OCs in periodontal disease and to determine the extent to which self-selection bias and oral health behaviors affect the initiation or progression of periodontal disease.

\section{ACKNOWLEDGMENTS}

The authors gratefully acknowledge colleagues at the University of Michigan: Drs. Robert Eber, Department of Periodontics/Prevention/Geriatrics; Nancy Reame, School of Nursing; Myra Kim, Center for Statistical Consultation and Research; and Brian Burt, Department of Epidemiology, for their support of this project and Drs. George Taylor, Department of Cariology, Restorative Sciences, and Endodontics, and Russell Taichman, Department of Periodontics/Prevention/ Geriatrics, for their critical review of the manuscript. This investigation was supported by Training Grant T32 07157 from the National Institute of Dental and Craniofacial Research, National Institutes of Health, Bethesda, Maryland.

\section{REFERENCES}

1. Hatcher R. Contraceptive Technology, 17th ed. New York: Ardent Media; 1999:405-466.

2. Petitti DB. Epidemiologic assessment of the risks of oral contraception. J Reprod Med 1986;31:887-891.

3. Davis A, Wysocki S. Clinician/patient interaction: Communicating the benefits and risks of oral contraceptives. Contraception 1999;59:39S-42S.

4. Sherif K. Benefits and risks of oral contraceptives. Am J Obstet Gynecol 1999;180:S343-S348.

5. Burkman R, Schlesselman JJ, Zeiman M. Safety concerns and health benefits associated with oral contraception. Am J Obstet Gynecol 2004;190:S5-S22.

6. Mariotti A. Sex steroid hormones and cell dynamics in the periodontium. Crit Rev Oral Biol Med 1994;5: 27-53.

7. Zachariasen RD. The effect of elevated ovarian hormones on periodontal health: Oral contraceptives and pregnancy. Women Health 1993;20:21-30. 
8. Sooriyamoorthy M, Gower DB. Hormonal influences on gingival tissue: Relationship to periodontal disease. $J$ Clin Periodontol 1989;16:201-208.

9. Zacharias S, Aguilena H, Assanzo JR, Zantu J. Effects of hormonal and non-hormonal contraceptives on lactation and incidence of pregnancy. Contraception 1984;30:203-206

10. Amar S, Chung KM. Influence of hormonal variation on the periodontium in women. Periodontol 2000 1994;6: 79-87.

11. Lindhe J, Bjorn AL. Influence of hormonal contraceptives on the gingiva of women. J Periodontal Res 1967;2: 1-6.

12. El-Ashiry GM, el-Kafrawy AH, Nasr MF, Younis N. Effects of oral contraceptives on the gingiva. J Periodontol 1971;42:273-275.

13. Kalkwarf KL. Effect of oral contraceptive therapy on gingival inflammation in humans. J Periodontol 1978;49: 560-563.

14. El-Ashiry GM, el-Kafrawy AH, Nasr MF, Younis N. Comparative study of the influence of pregnancy and oral contraceptives on the gingivae. Oral Surg Oral Med Oral Pathol 1970;30:472-475.

15. Das AK, Bhowmick S, Dutta A. Oral contraceptives and periodontal disease. J Indian Dent Assoc 1971; 43:47-53.

16. Pankhurst CL, Waite IM, Hicks KA, Allenu Y, Harkness RD. The influence of oral contraceptive therapy on the periodontium - duration of drug therapy. J Periodontol 1981;52:617-620.

17. Knight GM, Wade AB. The effects of hormonal contraceptives on the human periodontium. J Periodontal Res 1974;9:18-22.

18. Vittek J, Gordon GG, Rappaport SC, Munnangi PR, Southren AL. Specific progesterone receptors in rabbit gingiva. J Periodontal Res 1982;17:657-661.

19. Lindhe J, Bränemark PI, Lundskog J. Changes in vascular proliferation after local application of sex hormones. $J$ Periodontal Res 1967;2:266-272.

20. Lindhe J, Bränemark PI. Changes in vascular permeability after local application of sex hormones. J Periodontal Res 1967;2:259-265.

21. Lindhe J, Bränemark PI. Changes in microcirculation after local application of sex hormones. J Periodontal Res 1967;2:185-193.

22. Thorogood M. Risk of stroke in users of oral contraceptives. JAMA 1999;281:1255-1256.

23. Schwartz SM, Petitti DB, Siscovick DS, et al. Stroke and use of low-dose oral contraceptives in young women: A pooled analysis of two US studies. Stroke 1998;29: 2277-2284.

24. Connell EB. Oral contraceptives: The current risk-benefit ratio. J Reprod Med 1998;29:513-523.

25. Hannaford PC, Owen-Smith V. Using epidemiological data to guide clinical practice: Review of studies on cardiovascular disease and use of combined oral contraceptives. Br Med J 1998;316:984-987.

26. Klinger G, Eick S, Klinger G, et al. Influence of hormonal contraceptives on microbial flora of the gingival sulcus. Contraception 1998;57:381-384.

27. U.S. Department of Health and Human Services. National Center for Health Statistics. First National Health and Nutrition Examination Survey (NHANES I), 1971-1975. Hyattsville, MD: Centers for Disease Control and Prevention. Available at: http://www.cdc.gov/nchs/nhanes. htm; accessed April 22, 2002.

28. Third National Health and Nutrition Examination Survey,
1988-1994. NHANES III data file (CD-ROM): Hyattsville, MD; Centers for Disease Control and Prevention. 1996; Public use data file documentation number 76200.

29. U.S. Public Health Service. National Center for Health Statistics. Plan and Operation of a Health Examination Survey: United States, 1988-1994. Washington, DC: Government Printing Office; 1994. Number 32.

30. Miller HW. Plan and Operation of the Health and Nutrition Examination Survey, United States, 1971-1973. Vital Health Stat 1, No. 10b. Hyattsville, MD: U.S. Department of Health and Human Services; 1977.

31. Russell AL. A system for scoring prevalence and incidence of periodontal disease. J Dent Res 1956;35: 350-359.

32. Douglass C, Gillings D, Sollecito W, Gammon M. The potential for increase in the periodontal diseases of the aged population. J Periodontol 1983;54:721-730.

33. Borrell LN, Burt BA, Gillespie BW, Lynch J, Neighbors H. Periodontitis in the United States: Beyond black and white. J Public Health Dent 2002;62:92-101.

34. Ezzati T, Massey J, Waksburg J, et al. Sample Design: Third National Health and Nutrition Examination Survey. Hyattsville, MD: National Center for Health Statistics; 1992.

35. Chasan-Taber L, Stampfer MJ. Epidemiology of oral contraceptives and cardiovascular disease Ann Intern Med 1998;128:467-477.

36. Samant A, Malik C, Chabra SK, Devi PK. Gingivitis and periodontal disease in pregnancy. $J$ Periodontal Res 1976;47:415-418.

37. Löe H, Silness J. Periodontal disease in pregnancy. I. Prevalence and severity. Acta Odontol Scand 1963;21: 533-551.

38. Hugoson A. Gingivitis in pregnant women. A longitudinal clinical study. Odontol Revy 1971;22:65-84.

39. Raber-Durlacher JE, Leene W, Palmerbouva CCR, Raber J, Abraham-Inpijn L. Experimental gingivitis during pregnancy and post partum: Immuno-histochemical aspects. J Periodontol 1983;64:211-218.

40. Armitage GC. Development of a classification system for periodontal diseases and conditions. Ann Periodontol 1999;4:1-6.

41. Beck JD, Löe H. Epidemiological principles in studying periodontal diseases. Periodontol 2000 1993;2: 34-45.

42. Preshaw PM, Knutsen MA, Mariotti A. Experimental gingivitis in women using oral contraceptives. J Dent Res 2001;80:2011-2015.

43. Tilakaratne A, Soory M, Ranasinghe AW, Corea SMX, Ekanayake SL, de Silva M. Effects of hormonal contraceptives on the periodontium, in a population of rural Sri-Lankan women. J Clin Periodontol 2000; 27: 753-757.

44. Hunt RJ. The efficiency of half-mouth examinations in estimating the prevalence of periodontal disease. J Dent Res 1987;66:1044-1048.

45. Albandar JM, Kingman A. Gingival recession, gingival bleeding, and dental calculus in adults 30 years of age and older in the United States, 1988-1994. J Periodontol 1999;70:34-40.

46. Reinhardt RA, Payne JB, Maze CA, Patil KD, Gallagher SJ, Mattson JS. Influence of estrogen and osteopenia/ osteoporosis on clinical periodontitis in postmenopausal women. J Periodontol 1999;70:823-828.

47. Norderyd OM, Grossi SG, Machtei EE, et al. Periodontal status of women taking postmenopausal estrogen 
supplementation. J Periodontol 1993;64:957-962.

48. Barrett-Connor E. Hormone replacement therapy. $\mathrm{Br}$ Med J 1998;317:457-461.

49. Krall EA, Dawson-Hughes B, Hannan MT, Wilson WPF, Kiel DP. Post-menopausal estrogen replacement and tooth retention. JAMA 1997;102:536-542.

50. Wilkins K, Johansen H, Beaudet MP, Neutel CI. Oral contraceptive use. Health Rep 2000;11:25-37.

51. Writing Group for the Women's Health Initiative Investigators. Risks and benefits of estrogen plus progestin in healthy postmenopausal women: Principal results from the Women's Health Initiative randomized controlled clinical trial. JAMA 2002;288:321-333.

52. Barrett-Connor E, Grady D. Hormone replacement therapy, heart disease, and other considerations. Annu Rev Public Health 1998;19:55-72.

53. Henderson BE, Paganini-Hill A, Ross RK. Decreased mortality in users of estrogen replacement therapy. Arch Intern Med 1991;151:75-78.

54. Grodstein F, Stampfer MJ, Colditz GA, et al. Postmenopausal hormone therapy and mortality. N Engl $J$ Med 1997;336:1769-1775.

55. Humphrey LL, Chan B, Sox HC. Postmenopausal hormone replacement therapy and the primary prevention of cardiovascular disease. Ann Intern Med 2002;137: 273-284.

56. Grodstein F, Clarkson TB, Manson JE. Understanding the divergent data on postmenopausal hormone therapy. $N$ Engl J Med 2003;348:645-650.
Correspondence: Dr. L. Susan Taichman, Department of Periodontics, Prevention, and Geriatrics, University of Michigan, 1011 N. University Ave., Room 3323D, Ann Arbor, MI 481091078. Fax: 734/763-5503; e-mail: hipolite@umich.edu.

Accepted for publication January 17, 2005. 